\title{
Stereoselective synthesis of 2,3-disubstituted dihydrobenzofuran using alkyne Prins type cyclization to vinylogous carbonates
}

\author{
SANTOSH J GHARPURE* and V PRASATH \\ Department of Chemistry, Indian Institute of Technology Madras, Chennai 600036, India \\ e-mail: sjgharpure@iitm.ac.in
}

\begin{abstract}
An intramolecular, alkyne Prins type cyclization of vinylogous carbonates derived from $o$-alkynyl phenols is developed for the stereoselective construction of trans-2,3-disubstituted dihydrobenzofuran derivatives. Strong Lewis acids like TMSOTf catalyse this reaction efficiently. The presence of mildly electron donating groups on aryl rings increases the efficiency of the reaction.
\end{abstract}

Keywords. Vinylogous carbonates; Prins cyclization; Lewis acids; Sonogashira coupling.

\section{Introduction}

2,3-Disubstituted dihydrobenzofuran moiety is ubiquitous in nature and molecules possessing this skeleton display remarkably diverse biological activity. Many of these natural products are constituents of traditional medicines and have been implicated with diverse biological activity such as antimicrobial, ${ }^{1}$ antioxidant, ${ }^{2}$ antimitotic, ${ }^{3}$ antiangiogenic, ${ }^{4}$ neuritogenic ${ }^{5}$ and even HIV integrase inhibition activity. ${ }^{6}$ As a result, a variety of methods have been developed over the years for the stereoselective synthesis of this motif. ${ }^{7}$ Acid catalysed $[3+2]$ cycloaddition of styrene derivatives with quinones ${ }^{8}$ cyclodehydration of hydroxyphenols, ${ }^{9}$ anion or radical induced cyclization of substituted iodophenols, ${ }^{10} \mathrm{Rh}(\mathrm{I})$ catalysed catalytic $\mathrm{C}-\mathrm{H}$ insertion, ${ }^{11}$ reactions of 2-hydroxyaryl- $\alpha, \beta$-unsaturated ketones with dimethylsulfonium carbonylmethylides, ${ }^{12}$ Pd-catalysed cyclizations ${ }^{13}$ and reduction of benzofurans ${ }^{14}$ are some of the prominent methods used for the synthesis of 2,3-disubstituted dihydrobenzofurans. Chiral $\mathrm{Rh}(\mathrm{II})$-catalysed intramolecular $\mathrm{C}-\mathrm{H}$ insertion reaction has also been reported for enantioselective synthesis of this motif. ${ }^{15}$ Though majority of these methods give access to cis isomer of 2,3-disubstituted dihydrobenzofuran, it is the trans isomer which is more prevalent in many of the natural products. All these methods have their advantages but many suffer from moderate diastereoselectivity. Thus, there is still need

\footnotetext{
${ }^{*}$ For correspondence
}

for developing highly diastereoselective strategies for this important class of molecules. Over the years, Prins cyclization has emerged as a useful method for the synthesis of tetrahydropyrans (THPs) and tetrahydrofurans (THFs). ${ }^{16}$ Vinylogous carbonate, which has proved to be excellent functional group for the synthesis of cyclic ethers under radical ${ }^{17}$ and anionic conditions, ${ }^{18}$ has also been found to be useful in the Lewis/Bronsted acid mediated Prins cyclization leading to THP derivatives. ${ }^{19}$ Even though most of the efforts on Prins cyclization used olefins; alkynes too have been shown to participate efficiently in the synthesis of THFs and THPs. ${ }^{20}$ In continuation of our interest on using vinylogous carbonates in the synthesis of cyclic ethers, ${ }^{21}$ particularly under non-radical conditions, ${ }^{22}$ we describe here an efficient and a highly diastereoselective synthesis of trans-2,3-disubstituted dihydrobenzofuran employing alkyne Prins cyclization to vinylogous carbonates.

\section{Results and discussion}

Recently, Cho et al. reported TMSOTf mediated synthesis of 5- and 6-exocyclic products, cis-2,3,5trisubstituted THFs, and cis-2,3,6-trisubstituted THPs by Prins type reaction between terminally substituted alkynyl alcohols and aldehydes. ${ }^{20}$ When this type of reaction was attempted by them with 2-alkynylphenols $\mathbf{1}$ with aldehydes $\mathbf{2}$ in the presence of TMSOTf, it generated the chalcones $\mathbf{3}$, chroman-4-ones $\mathbf{4}$ and hydrated products $\mathbf{5}$ depending on the substituent on the alkyne in moderate yields (scheme 1). ${ }^{23}$ These products are 


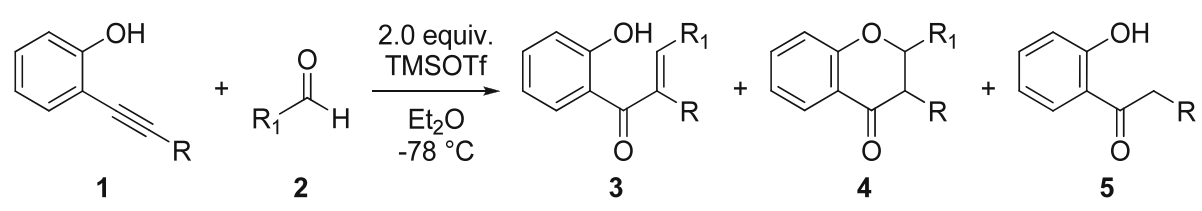

Scheme 1. TMSOTf-Promoted addition of alkynes to aldehydes.

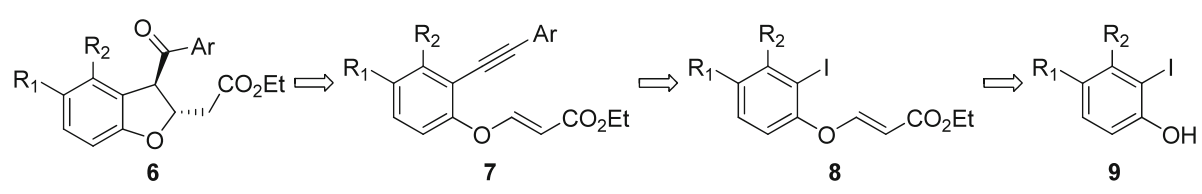

Scheme 2. Retrosynthesis for 2,3-disubstituted dihydrobenzofurans.<smiles>Oc1ccccc1I</smiles>

$9 a$

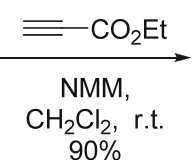

$90 \%$

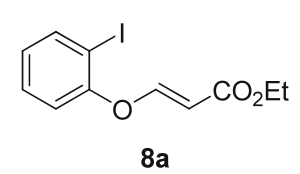

$8 \mathbf{a}$

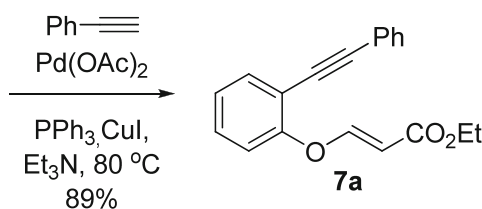

$89 \%$

Scheme 3. Synthesis of the vinylogous carbonate 7a.

formed by the reaction of alkyne directly with the aldehyde rather than by formation of oxonium ion from phenol and aldehyde followed by subsequent cyclization.

We envisioned that if the phenolic $\mathrm{OH}$ of 2alkynylphenol is engaged in the reaction for generating oxonium ion in the presence of Lewis acid, the reaction could lead to 2,3-disubstituted dihydrobenzofuran via a
Prins type cyclization. However, this oxonium ion generation by intermolecular reaction of a phenol and an aldehyde is non-trivial. To circumvent this problem, we argued that the 2,3-disubstituted dihydrobenzofurans 6 could be readily assembled by carrying out intramolecular alkyne Prins cyclization of the alkynyl vinylogous carbonates 7 using an appropriate Lewis acid

Table 1. Optimization of the alkyne Prins cyclization for the synthesis of 2,3disubstituted dihydrobenzofurans.<smiles>CCOC(=O)/C=C/Oc1ccccc1C#Cc1ccccc1</smiles>

$7 a$<smiles>CCOC(=O)C[C@H]1Oc2ccccc2C1C(=O)c1ccccc1</smiles>

6a

\begin{tabular}{llcccc}
\hline S.No & Lewis acid & Equiv. & Time $(\mathrm{h})$ & ${\text { Yield }(\%)^{\mathrm{a}}}$ & d.r. $^{\mathrm{b}^{2}}$ \\
\hline 1 & $\mathrm{BF}_{3} \cdot \mathrm{OEt}_{2}$ & 1.1 & 24 & 74 & $(\geq 19: 1)$ \\
2 & $\mathrm{TMSOTf}$ & 1.1 & 6 & 79 & $(\geq 19: 1)$ \\
3 & $\mathrm{TMSOTf}$ & 1.8 & 5 & 65 & $(\geq 19: 1)$ \\
4 & $\mathrm{TiCl}_{4}$ & 1.1 & 15 & 30 & $(\geq 19: 1)$ \\
5 & $\mathrm{FeCl}_{3}$ & 1.1 & 24 & $0^{\mathrm{c}}$ & - \\
6 & $\mathrm{CF}_{3} \mathrm{SO}_{3} \mathrm{H}$ & 1.1 & 15 & 44 & $(\geq 19: 1)$ \\
7 & $\mathrm{CF}_{3} \mathrm{CO}_{2} \mathrm{H}$ & 1.1 & 24 & $0^{\mathrm{c}}$ & - \\
\hline
\end{tabular}

${ }^{\mathrm{a}}$ Isolated yield. ${ }^{\mathrm{b}}$ Determined on crude reaction mixture by ${ }^{1} \mathrm{H}$ NMR. ${ }^{\mathrm{c}}$ Unreacted starting material recovered 
Table 2. Synthesis of the iodo vinylogous carbonates 8 .

\begin{tabular}{|c|c|c|c|c|}
\hline$R$ & $\mathrm{H}$ & $\underset{\underset{\text { r.t. }}{\mathrm{NMM}, \mathrm{CH}_{2} \mathrm{Cl}_{2}}}{\stackrel{\mathrm{CO}_{2} \mathrm{Et}}{\longrightarrow}}$ & $\underbrace{R^{2}}$ & \\
\hline Sr. No. & $\mathrm{R}^{1}$ & $\mathrm{R}^{2}$ & Product & Yield $(\%)^{\mathrm{a}}$ \\
\hline 1. & $\mathrm{Me}$ & $\mathrm{H}$ & $8 b$ & 89 \\
\hline 2. & ${ }^{t} \mathrm{Bu}$ & $\mathrm{H}$ & $8 c$ & 87 \\
\hline 3. & $\mathrm{Cl}$ & $\mathrm{H}$ & $8 d$ & 90 \\
\hline 4. & $\mathrm{Ph}$ & $\mathrm{H}$ & $8 e$ & $64^{\mathrm{b}}$ \\
\hline 5. & $\mathrm{C}_{4} \mathrm{H}_{4}$ & $\mathrm{C}_{4} \mathrm{H}_{4}$ & $8 f$ & 90 \\
\hline
\end{tabular}

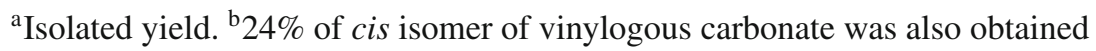

(scheme 2). It was rationalized that the vinylogous carbonate moiety derived from phenol will serve as a surrogate for oxonium ion. The alkynyl vinylogous carbonates 7 in turn can be synthesized from the corresponding iodides $\mathbf{8}$ by Sonogashira coupling reaction. The $o$-iodo vinylogous carbonates $\mathbf{8}$ can be obtained from substituted $o$-iodophenol derivatives $\mathbf{9}$.

To test the hypothesis, synthesis of the alkyne $7 \mathbf{a}$ was initiated. Thus, reaction of $o$-iodophenol (9a) with ethyl propiolate in the presence of $\mathrm{N}$-methylmorpholine (NMM) gave the $o$-iodo vinylogous carbonate 8a in good yield. The iodo vinylogous carbonate 8a was then subjected to Pd catalysed Sonogashira coupling reaction to furnish the enyne $\mathbf{7 a}$ in excellent yield (scheme 3).

The feasibility of the envisaged intramolecular alkyne Prins cyclization of enyne 7a was studied next using various Lewis acids. Reaction of the enyne 7a with $\mathrm{BF}_{3} \cdot \mathrm{OEt}_{2}$ in $\mathrm{CH}_{2} \mathrm{Cl}_{2}$ at $0^{\circ} \mathrm{C}$ gratifyingly gave the 2,3-disubstituted dihydrobenzofuran $\mathbf{6 a}$ in good yield and excellent diastereoselectivity (table 1, entry 1). The reaction time was substantially reduced when TMSOTf was used as the Lewis acid for effecting this transformation with slight increase in yield (table 1, entry 2). Increasing the amount of TMSOTf did not show further improvements in the reaction time or the yield (table 1, entry 3 ). When $\mathrm{TiCl}_{4}$ was used to promote the reaction, it resulted in the formation of dihydrobenozofuran $\mathbf{6 a}$ in only $30 \%$ yield; whereas $\mathrm{FeCl}_{3}$ was found to be ineffective in this reaction (table 1, entries 45). While a strong Bronsted acid like $\mathrm{CF}_{3} \mathrm{SO}_{3} \mathrm{H}$ gave moderate yield albeit with good diastereoselectivity, the milder trifluoroacetic acid failed to promote the alkyne Prins cyclization (table 1, entries 6-7). Based on these results it was clear that mild Lewis or Bronsted acids are not good for effecting this alkyne Prins cyclization and hence TMSOTf was chosen as the catalyst of choice for further study. The structure of the dihydrobenzofuran derivative 6a rests secured from its spectral data. ${ }^{1}$ The stereochemistry of dihydrobenzofuran $\mathbf{6 a}$ was ascertained as trans, based on coupling constants of $\mathrm{H}_{2}$ and $\mathrm{H}_{3}$ protons $(J=6.3 \mathrm{~Hz})$ which was comparable with that reported earlier for similar compounds. Further support was provided by the NOE studies in which irradiation of $\mathrm{H}_{3}$ proton resulted in enhancement in the $\mathrm{CH}_{2} \mathrm{CO}_{2}$ Et intensity and vice versa (see supporting information).

To study the scope of this alkyne Prins cyclization for the synthesis of trans-2,3-disubstituted dihydrobenzofurans, synthesis of various vinylogous carbonates $\mathbf{8}$ was undertaken. Various iodophenols 9 were subjected to Michael addition with ethyl propiolate to give the corresponding $o$-iodo vinylogous carbonates 8 (table 2). In general, the formation of iodo vinylogous carbonates 8 was uneventful and in all the cases excellent yields were obtained. Only in the case of the iodophenol $9 \mathrm{e}$, the reaction led to formation of a mixture of cis and trans vinylogous carbonates $\mathbf{8 e}$ which could be separated by column chromatography on silica gel.

Table 3 describes the scope of this intramolecular alkyne Prins cyclization to vinylogous carbonates. In all the cases, the requisite alkynyl vinylogous carbonates 7 were prepared by Sonogashira coupling of the iodide $\mathbf{8}$ with aryl acetylene 10 using $\mathrm{Pd}(\mathrm{OAc})_{2} / \mathrm{PPh}_{3} / \mathrm{CuI}$ as the catalyst. In general, the reaction proceeded smoothly furnishing the coupling products 7 .

\footnotetext{
${ }^{1}$ All the compounds exhibited spectral data consistent with their structures, see supporting information.
} 
Table 3. Scope of the alkyne Prins cyclization for the synthesis of 2,3-disubstituted dihydrobenzofurans.<smiles>[R]c1ccc(O/C=C/C(=O)OC)c(I)c1[R]</smiles>

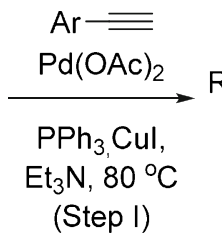

(Step I)<smiles>[Y]c1ccc(O/C=C/C(=O)O[Tl])c(C#CBr)c1[R]</smiles>

S. No. $\quad$ Iodide vinylogous carbonate (8) Aryl acytelene (10) $\quad \frac{\text { Yield }(\%)^{\mathrm{a}}}{\text { Step I } \quad \text { Step II }}$<smiles>[R]c1ccc2c(c1[R])C(C(=O)[Al])[C@H](CC(=O)OCC)O2</smiles>

6
2

3

4

5

6

7

$8 b$

$8 c$
$\mathrm{C}_{6} \mathrm{H}_{5} \mathrm{CCH}$

$\mathrm{C}_{6} \mathrm{H}_{5} \mathrm{CCH}$

$\mathrm{C}_{6} \mathrm{H}_{5} \mathrm{CCH}$

$\mathrm{C}_{6} \mathrm{H}_{5} \mathrm{CCH}$

$\mathrm{C}_{6} \mathrm{H}_{5} \mathrm{CCH}$

$p-\mathrm{MeC}_{6} \mathrm{H}_{4} \mathrm{CCH}$

$p-\mathrm{MeC}_{6} \mathrm{H}_{4} \mathrm{CCH}$

$p-\mathrm{MeC}_{6} \mathrm{H}_{4} \mathrm{CCH}$
86

82

83

90

87

88

92

91
53

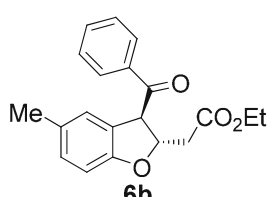

60<smiles>CCOC(=O)CC1Oc2ccc(C(C)(C)C)cc2C1C(=O)c1ccccc1</smiles>

35<smiles>CCOCC1Oc2ccc(Cl)cc2C1C(=O)c1ccccc1</smiles><smiles>CCOC(=O)CC1Oc2ccc(-c3ccccc3)cc2C1C(=O)c1ccccc1</smiles>

53

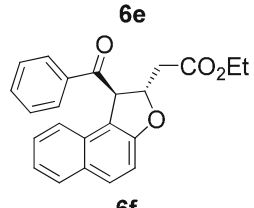

81

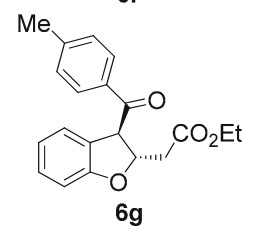

69<smiles>CCOC(=O)CC1c2ccc(C)cc2OC1C(=O)c1ccc(C)cc1</smiles>

64

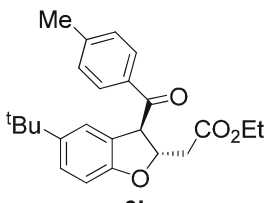


Table 3. (continued).

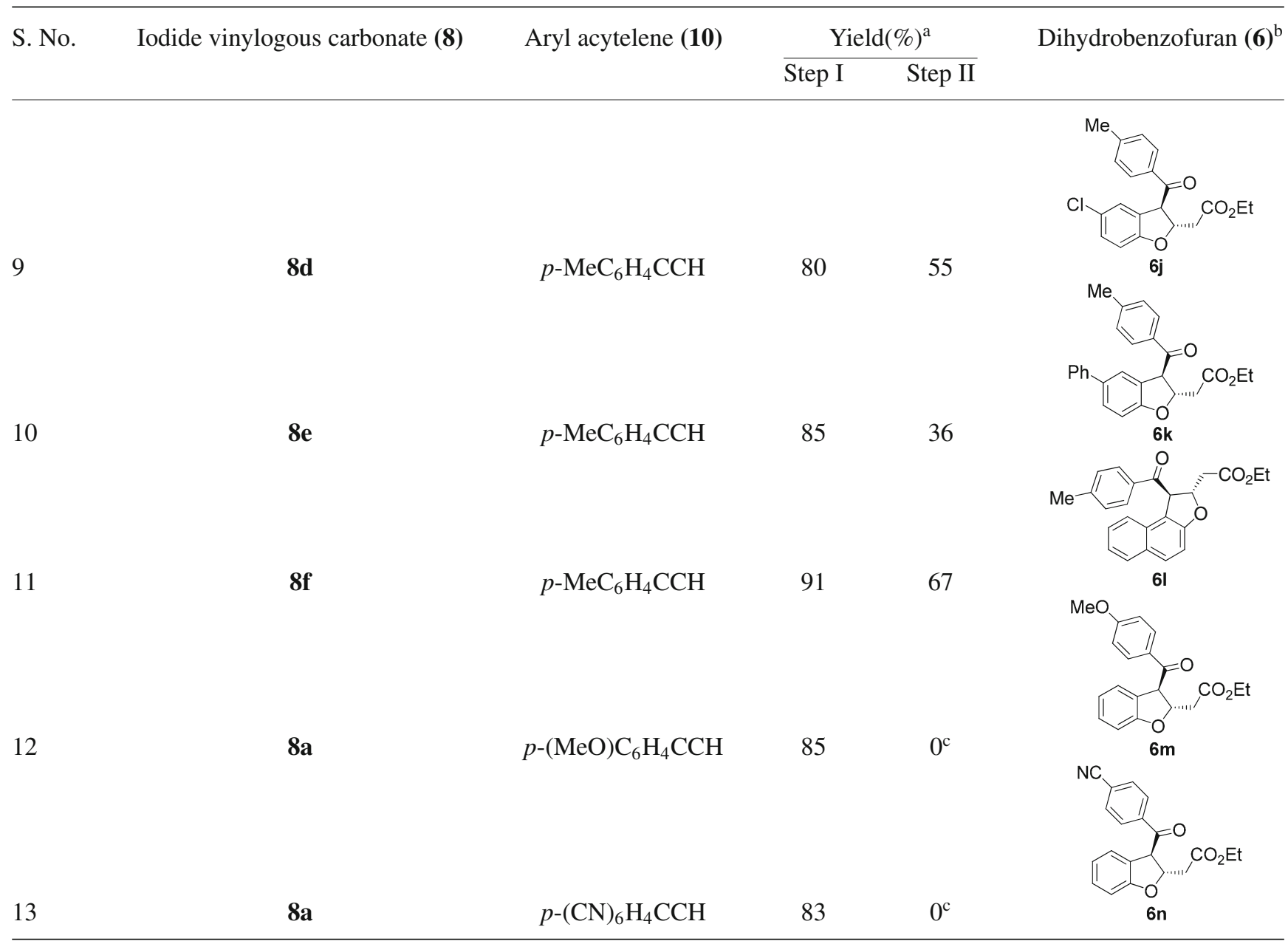

${ }^{a}$ Isolated yields. ${ }^{b}$ d.r. was determined on crude reaction mixture by ${ }^{1} \mathrm{H}$ NMR and found to be $\geq 19: 1$ in all cases. ${ }^{\mathrm{c}}$ Decomposition during the reaction

The alkyne Prins cyclization was studied on these alkynyl vinylogous carbonates 7 . The reaction was found to work very well with mildly electron donating alkyl substituents on any of the aryl rings (table 3, entries 1-2 and 6-8). The presence of electron withdrawing chlorine on one of the aryl ring led to the formation of the product in moderate yield (table 3, entry 4). Interestingly, when a methyl substituent was introduced in the other aryl ring, the yield of the reaction showed some improvement (table 3, entry 9). Phenyl substitution on the aryl ring in general resulted in the moderate efficiency (table 3, entries 4 and 10); whereas the naphthyl ring bearing substrates furnished the dihydrobenzofurans $\mathbf{6} \mathbf{f}$ and $\mathbf{6} \mathbf{l}$ in excellent yields. Interestingly, the presence of relatively stronger electron releasing $(\mathrm{OMe})$ or electron withdrawing group $(\mathrm{CN})$ in one of the aryl ring led to extensive decomposition and no dihydrobenzofuran formation could be detected (table 3 , entries 12-13).
Formation of the 2,3-disubstituted dihydrobenzofuran can be explained with the help of the mechanism as shown in figure 1. Initially, the carbonyl group of the vinylogous carbonate moiety complexes with the Lewis acid leading to the formation of the oxonium ion 10. This oxonium ion $\mathbf{1 0}$ is trapped by alkyne in a Prins type reaction generating a vinyl cation $\mathbf{1 1}$. The vinyl cation 11 gets trapped with water during the work-up generating enol $\mathbf{1 2}$ which on tautomerization generates the 2,3-disubstituted dihydrobenzofuran 6. Formation of trans isomer during tautomerization is perhaps the outcome of the protonation event which happens in such a way so as to minimize steric repulsion between the substituents on $\mathrm{C} 2$ and $\mathrm{C} 3$ of the dihydrobenzofuran moiety. It is pertinent to mention that changing the solvent from $\mathrm{CH}_{2} \mathrm{Cl}_{2}$ to ether did not result in formation of triflate derivative by trapping of vinyl cation 11 with the triflate ion as observed by Cho and co-workers. 

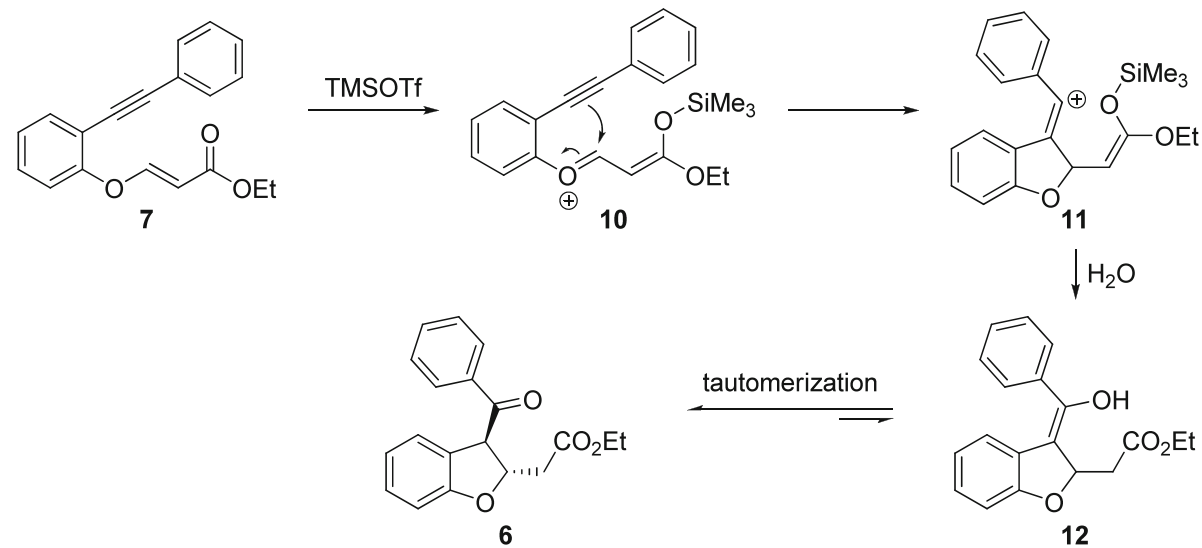

Figure 1. Mechanism of formation for trans-2,3-disusbstituted dihydrobenzofuran.

\section{Conclusion}

We have developed a highly stereoselective synthesis of trans-2,3-disubstituted dihydrobenzofurans using alkyne Prins cyclization to vinylogous carbonates. Generation of the oxonium ion by the intermolecular reaction of the phenolic hydroxyl group with an aldehyde is in general a non-trivial task. Notable feature of this study is that not only was this task made easy by engaging phenolic $\mathrm{OH}$ in the vinylogous carbonate moiety but also the reactivity of the generated oxonium ion was harnessed in the stereoselective transformation. The reaction is found to be sensitive to substituents on the aryl ring. In general, mildly electron donating groups are found to give better reactivity profile. Further efforts are underway to understand substituent effects and optimize these reactions for improving the substrate scope and applying them in target directed synthesis.

\section{Supporting information}

Synthetic procedures and characterization data for all the new compounds are given as electronic supporting information. See www.ias.ac.in/chemsci for details.

\section{Acknowledgements}

We thank the Department of Science and Technology (DST) and Council of Scientific and Industrial Research (CSIR), New Delhi for financial support. We appreciate the NMR facility provided by the DST under the IRPHA program to the Department of Chemistry, IIT Madras. We are grateful to CSIR, New Delhi for the award of a research fellowship to VP.

\section{References}

1. Pauletti P M, Arajo A R, Young M C M, Giesbrecht A M and Bolzani V S 2000 Phytochemistry 55597

2. Kikuzaki H, Kayano S, Fukutsuka N, Aoki A, Kasamatsu K, Yamasaki Y, Mitani T and Nakatani N J 2004 Agric. Food Chem. 52344

3. Pieters L, Van Dyck S, Gao M, Bai R, Hamel E, Vlietinck A and Lemire G 1999 J. Med. Chem. 425475

4. Apers S, Vlietinck A and Pieters L 2003 Phytochem. Rev. 2201

5. Shin J S, Kim Y M, Hong S S, Kang H S, Yang Y J, Lee D K, Hwang B Y, Ro J S and Lee M K 2005 Arch. Pharm. Res. 281337

6. Abd-Elazem I S, Chen H S, Bates R B and Huang R C C 2002 Antiviral Res. 5591

7. Graening T and Thrun F 2008 Comprehensive hetereocyclic chemistry III 3553 Katritzky A R, Taylor R J K, Ramsden C A and Scriven E F V, Eds, Elsevier and references cited therein

8. (a) Sefkow M 2003 Synthesis 2595; (b) Engler T A, Chai W and LaTessa K O 1996 J. Org. Chem. 61 9297; (c) Engler T A, Chai W and Lynch K O Jr 1995 Tetrahedron Lett. 367003

9. Bertolini F, Crotti P, Bussolo V D, Macchia F and Pineschi M 2007 J. Org. Chem. 727761

10. (a) Nakao J, Inoue R, Shinokubo H and Oshima K 1997 J. Org. Chem. 62 1910; (b) Vaillard S E, Postigo A and Rossi R A 2002 J. Org. Chem. 67 8500; (c) Sanz R, Miguel D, Martinez A and Perez A 2006 J. Org. Chem. 714024

11. O'Malley S J, Tan K L, Watzke A, Bergman R G and Ellman J A 2005 J. Am. Chem. Soc. 12713496

12. Malik S, Nadir U K and Pandey P S 2009 Tetrahedron Lett. 653958

13. For examples, see: (a) Kondo $\mathrm{Y}$, Sakamoto $\mathrm{T}$ and Yamanaka H 1989 Heterocycles 29 1013; (b) Lutjens H and Scammells P J 1998 Tetrahedron Lett. 39 6581; (c) Nan Y, Miao H and Yang Z 2000 Org. Lett. 2297

14. Fischer J, Savage G P and Coster M J 2011 Org. Lett. 13 3376 
15. (a) Garcia-Muoz S, lvarez-Corral M, Jimnez-Gonzlez L, Lpez-Snchez C, Rosales A, Muoz-Dorado M and Rodrguez-Garca I 2006 Tetrahedron 62 12182; (b) Natori Y, Tsutsui H, Sato N, Nakamura S, Nambu H, Shiro M and Hashimoto S 2009 J. Org. Chem. 74 4418; (c) Thalji R K, Ellman J A and Bergman R G 2004 J. Am. Chem. Soc. 1267192

16. For some reviews, see: (a) Olier C, Kaafarani M, Gastaldi S and Bertrand M P 2010 Tetrahedron 66 413; (b) Arundale E, Mikeska L A 1952 Chem. Rev. 51 505; (c) Adams D R and Bhatnagar S P 1977 Synthesis 661; (d) Snider B B 1991 In Comprehensive Organic Synthesis 2527 Trost B, Fleming I and Heathcook C H, Eds, Pergamon: New Yok, NY

17. (a) Lee E, Tae J S, Lee C and Park C M 1993 Tetrahedron Lett. 34 4831; (b) Hori N, Matsukura H, Matsuo G and Nakata T 1999 Tetrahedron Lett. 40 2811; (c) Evans P A, Raina S and Ahsan K 2001 Chem. Commun. 2504; (d) Leeuwenburgh M A, Litjens R E J N, Codée J D C, Overkleeft H S, Van der Marel G A and Van Boom J H 2000 Org. Lett. 2 1275; (e) Sibi M P, Patil K and Rheault T R E 2004 Eur. J. Org. Chem. 372; (f) Chakraborty T K, Samanta R and Ravikumar K 2007 Tetrahedron Lett. 486389 and references therein

18. Henderson D A, Collier P N, Gregoire P, Rzepa P, White A J P, Burrows J N and Barrett A G M 2006 J. Org. Chem. 71 2434; for some selected examples of Stetter reaction in the synthesis THF and THPs, see: (a) Ciganek E 1995 Synthesis 1311; (b) Frank S A, Mergott D J and Roush W R $2002 \mathrm{~J}$. Am. Chem. Soc. 124 2404; (c) Kerr M S, Read de Alaniz J and Rovis T 2002 J. Am. Chem. Soc. 124 10298; (d) Kerr M S and
Rovis T 2004 J. Am. Chem. Soc. 126 8876; (e) McErlean C S P and Willis A C 2009 Synlett 233 and references therein

19. (a) For a detailed investigation of the influence of structural parameters upon regio- and stereo-selectivity, see: Bennett C E, Figueroa R, Hart D J and Yang D 2006 Heterocycles 70 119; (b) Hart D J and Bennett C E 2003 Org. Lett. 5 1499; (c) Frater G, Muller U and Kraft P 2004 Helv. Chim. Acta 87 2750; (d) Kwon M S, Woo S K, Na S W and Lee E 2008 Angew. Chem. Int. Ed. 47 1733; (e) Nussbaumer C and Frater G 1987 Helv. Chim. Acta 70 396; (f) Barry C St J, Crosby S R, Harding J R, Hughes R A, King C D, Parker G D and Willis C L 2003 Org. Lett. 5 2429; (g) Barry C S, Elsworth J D, Seden P T, Bushby N, Harding J R, Alder R W and Willis C L 2006 Org. Lett. 83319

20. (a) Chavre S N, Choo H, Pae A N, Cha J H, Choi J H and Cho Y S 2006 Org. Lett. 8 3617; (b) Chavre S N, Choo H, Lee J K, Pae A N, Kim Y and Cho Y S 2008 J. Org. Chem. 737467

21. (a) Gharpure S J and Porwal S K 2008 Synlett 242; (b) Gharpure S J and Porwal S K 2011 Tetrahedron 67121

22. (a) Gharpure S J and Reddy S R B 2009 Org. Lett. 11 2519; (b) Gharpure S J, Shukla M K and Vijayasree U 2009 Org. Lett. 11 5466; (c) Gharpure S J and Reddy S R B 2010 Tetrahedron Lett. 51 6093; (d) Gharpure S J and Sathiyanarayanan A M 2011 Chem. Commun. 473625

23. Park J N, Ullapu P R, Choo H, Lee J K, Min S -J, Pae A N, Kim Y, Back D-J and Cho Y S 2008 Eur. J. Org. Chem. 5461 